\title{
CORPUS Corpus
}

Archivos virtuales de la alteridad americana

Vol 3, No $1 \mid 2013$

Enero / Junio 2013

Silvano Benito Moya, La Universidad de Córdoba en tiempos de reformas (1701-1810)

Córdoba, Centro de Estudios Históricos Prof. Carlos Segreti, 2011, 414 pp.

\section{Sebastián Perrupato}

\section{OpenEdition}

\section{Journals}

Edición electrónica

URL: http://journals.openedition.org/corpusarchivos/252

DOI: $10.4000 /$ corpusarchivos. 252

ISSN: 1853-8037

Editor

Diego Escolar

Referencia electrónica

Sebastián Perrupato, «Silvano Benito Moya, La Universidad de Córdoba en tiempos de reformas (1701-1810) », Corpus [En línea], Vol 3, No 1 | 2013, Publicado el 15 junio 2013, consultado el 22 septiembre 2020. URL : http://journals.openedition.org/corpusarchivos/252 ; DOI : https://doi.org/ $10.4000 /$ corpusarchivos.252

Este documento fue generado automáticamente el 22 septiembre 2020

Licencia Creative Commons: Atribución-NoComercial 2.5 Argentina (CC BY-NC 2.5 AR) 


\section{Silvano Benito Moya, La Universidad de Córdoba en tiempos de reformas (1701-1810)}

Córdoba, Centro de Estudios Históricos Prof. Carlos Segreti, 2011, 414 pp.

\section{Sebastián Perrupato}

\section{REFERENCIA}

Silvano Benito Moya, La Universidad de Córdoba en tiempos de reformas (1701-1810), Córdoba, Centro de Estudios Históricos Prof. Carlos Segreti, 2011, 414 pp.

1 La Universidad como parte de la sociedad surge en una relación dialógica en la que se articulan redes de poder y nuevas ideas. Sus características, las formas de organización y su estructura conservan, a menudo, rasgos muy antiguos, por ello el conocimiento de su origen y evolución nos permite explicar algunos rasgos contemporáneos (Buchbinder, 2008). Repensar la universidad nos obliga a repensar sus orígenes fundantes, al tiempo que las nuevas tendencias de investigación hacen necesario un replanteo multidisciplinar de las tesis clásicas sobre el tema. Entender el origen y la fundación de una universidad secular nos ayuda a comprender de algún modo los lineamientos de la aparente crisis de esta institución hoy.

2 La tradición universitaria argentina se inaugura con la fundación de la Universidad de Córdoba. Esta, como afirma Marcelo Vittarelli, adquiere un papel protagónico para la transformación de la sociedad en los cambiantes contextos que se viven en el Río de la Plata en el período que va del virreinato a la fundación del estado moderno argentino (Vitarelli, 2010).

3 La historiografía sobre la educación superior en tiempos de la colonia ha sido (y sigue siendo) variada. Pese a ello, su tendencia es marcadamente institucionalista, aunque en los últimos años podemos mencionar una propensión a analizar los contenidos y una 
preocupación por insertar estas instituciones en un contexto más amplio, en este caso, la segunda mitad del siglo XVIII.

4 La renovación historiográfica de los años ochenta trajo consigo nuevos planteos y análisis que, desde la historia social y cultural, abordaron el tema y ofrecieron nuevas discusiones alejadas de las que encarnaban el espíritu positivista de principios de siglo. Sin embargo, la Universidad de Córdoba no había sido estudiada como un todo dinámico donde los sujetos y los objetos del conocimiento interactúan mostrando la intima relación de lo social y lo cultural.

En su libro La Universidad de Córdoba en tiempos de reforma, Silvano Benito Moya revisa con detalle la evolución de la realidad tanto social como cultural de esta institución a lo largo del siglo XVIII. Se trata de parte de su tesis doctoral, en la que trabaja principalmente a partir de las conceptualizaciones de Roger Chartier, Armando Petrucci, Peter Burke y Thomas Kuhn.

6 El libro analiza dos tiempos en los que se evidencia la construcción del poder intrainstitucional y las tensiones entre los grupos locales y la Corona española. El primero está caracterizado por la regencia jesuita de la universidad (1701-1767) y el segundo por la regencia franciscana (1767-1808). Durante esta última se daría para el autor la cristalización del ideal borbónico de reforma dentro de la universidad, obedeciendo a una política de reforma vertical, que pretendía una mayor injerencia de la monarquía en las universidades, como consecuencia de su política regalista. Se buscaba formar una burocracia leal y consciente del nuevo ideario, a fin de que instrumentara eficiente y fielmente la reforma del nuevo Estado.

7 Desde una mirada sociocultural el autor estudia las constituciones, las personas, los lugares de trabajo, las fuentes $\mathrm{y}$, en definitiva, los actores que han participado en esta institución. Así, boletines de noticias, fundación de asociaciones y normativas: todo queda recogido por su atenta mirada a la que pareciera no escaparse ningún documento ni fuente. La prolijidad del trabajo de Benito Moya nos pone en situación y nos sirve de guía para entender la universidad como parte de un universo mayor, la sociedad. Universidad que no puede concebirse como una entelequia aislada, sino que es a la vez parte integrante de una corporación a la que reproduce.

El libro, divido en seis capítulos, trabaja en forma reveladora la relación entre los distintos elementos de la sociedad y los perfiles estudiantiles. En el primer capítulo el autor aborda la estructura y la dinámica de la población estudiantil. Este tema ya había sido trabajado previamente por Vera de Flachs (1987 y 1989); sin embargo, el aporte de Benito Moya radica en que los elementos culturales se mezclan con los análisis estadísticos muy bien documentados. Los planteos demográficos están satisfactoriamente desarrollados, aunque el análisis de los mismos no se realiza en profundidad y sus resultados dejan inconclusas muchas de las preguntas que originan su búsqueda inicial.

En el segundo capítulo el autor trabaja desde las categorías foucaultianas las concepciones de tiempo, disciplina y conflicto dentro de la universidad. Así plantea que la disciplina, los espacios y los horarios de las facultades se encuentran ordenados en función del modelo de uso del tiempo que se difundió rápidamente por el ámbito educativo del mundo moderno, por medio de tres procedimientos básicos: establecer ritmos, obligar a ocupaciones determinadas y reglar los ciclos de repetición (Foucault, 1976). 
En los capítulos tres y cuatro el autor retoma la línea de Roger Chartier, entendiendo la lectura y la escritura como parte de las prácticas culturales de la comunidad universitaria. Este francés postula que se debería definir un campo de lo social en el que circulan textos, producciones y normas culturales, a partir de los objetos, sus dispositivos y códigos (Chartier, 2006). En este sentido la apropiación de la lectura y escritura por parte de la comunidad universitaria se presenta como un modo de acumulación de poder y de legitimación de la diferenciación social. Así, los grupos establecen vínculos de relación con la sociedad en su conjunto y se apropian de los saberes de la lecto-escritura estableciendo redes de poder locales que hacen difícil el acceso a las políticas monárquicas.

9 En el capitulo cinco, Moya retoma de forma sintética la perspectiva revisionista que se habría dado en torno a la incidencia de las nuevas ideas en la universidad durante la década de 1750 (Furlong, 1952; Lertora Mendoza, 1979), tema que ya había trabajado en su primer libro (Benito Moya, 2000). Para el autor las cátedras tradicionales se ven tensionadas entre la escolástica y las nuevas corrientes filosófico-científicas que, heredadas de la Ilustración, intentan cambiar el paradigma científico vigente.

El último capítulo de la obra trabaja las relaciones de la universidad con la sociedad cordobesa. Si bien este tema ya había sido trabajado previamente (Endrek, 1966; Vera de Flachs, 1987, 1989) el autor posiciona a la población universitaria estudiantil y docente como actores políticos y los incorpora a un contexto de reformas en el que las tensiones entre el afuera y el adentro, las presiones políticas y la acción de la Corona modifican el esquema preestablecido haciendo tambalear el statu quo. En este sentido, debe destacarse el estudio de aspectos sociales y culturales de la población universitaria que realiza el autor; se interesa por la vida cotidiana de los estudiantes y los presenta no solo como individuos, sino como grupos interrelacionados que construyen un entramado donde se evidencian mecanismos de inclusión/exclusión.

11 En síntesis, la obra de Silvano Benito Moya nos acerca una nueva forma de aproximación a un tema arduamente discutido por la historiografía americana y española. Los nuevos enfoques del autor permiten entender la universidad como un complejo fenómeno en el que interactuaran diferentes grupos de poder que operan en función de una realidad más amplia, que excede los límites locales para situase como parte integrante de una Corona española cada vez más erosionada.

\section{BIBLIOGRAFÍA}

Benito Moya, S. (2000). Reformismo e Ilustración. Los Borbones en la Universidad de Córdoba. Córdoba: Centro de Estudios Históricos "Prof. Carlos S. A. Segreti"

Benito Moya, S. (2011). La Universidad de Córdoba en tiempos de reformas (1701-1810). Córdoba: Centro de Estudios Históricos "Prof. Carlos S. A. Segreti"

Buchbinder, P. (2008). La Universidad: breve introducción a su evolución histórica. Universidad

Nacional del Litoral. 
Chartier, R. (2006). Inscribir y borrar: cultura escrita y literatura (siglos XI-XVIII). Buenos Aires: Katz.

Endrek, E. (1966). El Mestizaje en Córdoba, siglo XVIII y principios del XIX. Córdoba: Universidad Nacional de Córdoba, Instituto de Estudios Americanistas.

Foulcaut, M. (1976). Vigilar y castigar. Nacimiento de la prisión. Buenos Aires: Siglo XXI.

Furlong, G. (1952). Nacimiento y desarrollo de la Filosofía en el Río de la Plata (1536-1810). Buenos Aires: Kraft.

Lértora Mendoza, C. A. (1979). Las fuentes utilizadas en la enseñanza de la filosofía en el período hispano. En Cuyo. Anuario de Historia del Pensamiento Argentino (Tomo XII, pp. 21-31). Mendoza: Universidad Nacional de Cuyo.

Vera de Flachs, M. C. (1987). El comportamiento de los claustros en la universidad de Cordoba 1664-1800). En AAVV, Universidades españolas y Americanas. Época colonial (pp. 553-567). Valencia: CSIC-Generalitat Valenciana.

Vera de Flachs, Maria. (1989) La universidad como factor de ascenso a la elite de poder en la America Hispana. En M. Peset y S. Albiña (Comp.), Claustros y estudiantes (Tomo II, pp. 399-426). Valencia: Universidad de Valencia.

Vitarrelli, M. (2010) Educación Superior y Cambio: La Universidad Argentina entre tensiones y transformaciones. San Luis: Mnemosyne.

\section{AUTORES}

SEBASTIÁN PERRUPATO

UNMdP/CONICET. Correo electrónico: sperrupato@gmail.com 